\title{
miR-449b inhibits the proliferation of SW1116 colon cancer stem cells through downregulation of CCND1 and E2F3 expression
}

\author{
YANTIAN FANG, XIAODONG GU, ZHENGYANG LI, JIANBIN XIANG and ZONGYOU CHEN \\ Department of General Surgery, Huashan Hospital Affiliated to Fudan University, Shanghai 200040, P.R. China
}

Received December 21, 2012; Accepted March 30, 2013

DOI: 10.3892/or.2013.2465

\begin{abstract}
Colorectal cancer is one of the leading causes of cancer-related mortality worldwide. Cancer stem cells are cell populations with stem cell nature presenting in tumor tissues and are the root of tumor formation and metastasis. CCND1 and E2F3 play important roles in cell cycle regulation. The 3'UTRs of CCND1 and E2F3 contain miR-449 binding sites. By transfecting pre-miR-449b and inhibiting miR-449b, we found that cell cycle, cell proliferation ability and cell cycle regulatory protein expression levels of colon cancer stem cells were altered. The correlation between CCND1, E2F3 and miR-449b showed that miR-449b could downregulate CCND1 and E2F3 expression. This, in turn, reduced the proliferative ability of colon cancer stem cells. These data suggest that miR-449b plays a tumor-suppressive role in colon cancer stem cells.
\end{abstract}

\section{Introduction}

Colon cancer is the third most common cancer worldwide (1) and it is also the fourth leading cause of mortality among all types of cancer in the United States (National Cancer Institute, 2009). Distant metastasis and recurrence of colon cancer are major causes of mortality $(2,3)$. With the advances in chemotherapy and the development of multi-disciplinary collaboration of treatment, the survival rate of colon cancer has increased significantly in recent years.

With the potential ability of self-renewal and the uncertain ability of differentiation, cancer stem cells are cell populations with a stem cell nature presenting in tumor tissue and are the root of tumor formation and metastasis (4-7). In recent years, a growing number of researchers have considered that cancer is a disease caused by the tumor stem cells (8). At present,

Correspondence to: Dr Jianbin Xiang or Dr Zongyou Chen, Department of General Surgery, Huashan Hospital Affiliated to Fudan University, 12 Wulumuqizhong Road, Shanghai 200040, P.R. China

E-mail: xjbzhw@163.com

E-mail: czyshhs@126.com

Key words: colon cancer, stem cell, proliferation, CCND1, E2F3 cancer stem cells are isolated with a variety of solid tumors and hematological neoplasms (5). This shows that the cancer stem cells are a common phenomenon in malignancies. Some studies have confirmed the presence of ovarian cancer stem cells. These cells are not sensitive to chemotherapy and radiotherapy (9-12). Qiang et al identified stem-like cells in human glioblastoma cell lines U251, U87MG, A172 (13).

microRNAs are a class of non-coding single-stranded RNA molecules in eukaryote. Through mediating degradation of target mRNA and inhibiting target mRNA translation, microRNA can regulate its target gene expression with post-transcriptional regulation. Through complementary combining with the target mRNA 3'-untranslated region (UTR) completely/incompletely (14-16), microRNAs regulate a variety of pathophysiological processes, such as stem cell differentiation, cell proliferation and tumor formation (17-20). Some microRNAs are closely associated with the ability of self-renewal and differentiation of cancer stem cells (21-23). Qian et al (24) successfully separated tumor stem cells from the lung tissue of mice, finding abnormal expression of miR-142-3p, miR-451, miR-106a, miR-142-5p, miR-15b, miR-20a, miR-106b, miR-25, miR-486 in the tumor stem cells. This suggests that miRNA regulates differentiation, invasion, apoptosis and several other characteristics. Silber et al (25) showed that miR-124 and miR-137 can induce differentiation of adult mouse neural stem cells, mouse oligodendrocyte glioma and human glioblastoma. microRNAs also regulate the biological function of tumor stem cells. In pancreatic cancer stem cells, miR-34 can inhibit the self-renewal ability of tumor stem cells by regulating the Notch and the Bcl-2 gene (26).

miR-449b can decrease SKOV32ip l adhesion ability, arrest cell cycle, increase the number of G1 phase cells, decrease the number of $\mathrm{S}$ phase cells and can downregulate cell cyclerelated proteins CDK6 and CDC25A (27). Bou et al (28) found a diminished expression of miR-449 in gastrin KO mice. Overexpressing miR-449, they showed a significant increase in the sub-G1 fraction indicative of apoptosis. Compared to normal human gastric tissues, they also discovered a loss of miR-449 expression (16). Through targeting pocket proteins, Chen et al (29) found that miR-449a plays a role as a tumor suppressor in human bladder cancer.

Cell cycle regulators and regulatory proteins play an important role in the tumor genesis process. CCND1 and E2F3 are key in cell cycle regulation. Cyclins, cyclin-dependent kinases and cyclin-dependent kinase inhibitors all have the ability to 
regulate cell cycle. The expression of CCND1 is closely linked to Ras, Raf, MAPK pathway and pRb family (30-34). The overexpression of CCND1 is the characteristic of a variety of human primary tumors (35-37), with significance for the diagnosis of cancer. E2F3 transcription factor is an important regulatory factor of cell cycle G1 to $\mathrm{S}$ phase $(38,39)$. E2F3 includes two protein products (E2F3a and E2F3b) sharing DNA binding. E2F3a is closely related to DNA synthesis and cell cycle progression. E2F3b is expressed throughout the cell cycle (39) and it is also linked to tumor genesis and proliferation (40). Studies have shown that E2F3 plays a role as an oncogene in most organizations (40-42). E2F3 overexpression can contribute to the formation of skin tumors in p53-deficient mice (43).

Based on the above, we first identified differentially expressing microRNAs in colon cancer stem cells and we then explored the relationship between differential expressing microRNA (miR-449b) in colon cancer stem cells and cell cycle regulation.

\section{Materials and methods}

Cell line and cell culture. Human colon cancer cell line SW1116 was obtained from the Shanghai Institute of Cell Biology, affiliated to the Chinese Academy of Sciences, Shanghai, China. The cell culture method was the same as the one we previously reported (44). We separated $\mathrm{CD} 133^{+} \mathrm{CD} 44^{+}$ and $\mathrm{CD} 133^{-} \mathrm{CD} 44^{-}$cells using the same method as we previously reported (44).

Total cellular RNA extraction. We used TRIzol (Invitrogen, Carlsbad, CA, USA) to extract total cellular RNA following the manufacturer's instructions. Extracted RNA samples were quantified with NanoDrop 1000 (NanoDrop Technologies, Wilmington, DE, USA). The extracted RNA samples were treated by DNase (Ambion, Austin, TX, USA) to remove genomic DNA contamination.

Analysis with microRNA chip. Human microRNA OneArray ${ }^{\circledR}$ v3 was used to analyze samples. microRNA chip performance and analysis methods were the same as we previously reported (44).

Real-time PCR. Total RNA was extracted as described above. We extracted RNA reverse transcribed into cDNA using a PrimeScript ${ }^{\circledR}$ RT Reagent kit (Takara, China). miRNA samples were first polyadenylated and were then reverse transcribed into cDNA with a One Step PrimeScript ${ }^{\circledR}$ miRNA cDNA Synthesis kit (Takara). Quantitative real-time PCR reaction was performed with 7000 Sequence Detection System (ABI) and with the reaction system, which included strand cDNA $(0.5 \mu \mathrm{l})$, forward and reverse primers (both $0.5 \mu \mathrm{l}$ ) and SYBR Green Supermix (12.5 $\mu \mathrm{l}$ ) (Tianjin, China). The formula $2^{-\Delta \Delta C T}$ values $\left(\Delta \mathrm{Ct}=\mathrm{Ct}^{\text {gene }}-\mathrm{Ct}^{\text {control }}\right)$ was used to calculate relative expressions.

Dual-luciferase report system assay. The fragments of pMIR- CCND1, pMIR-E2F3 and mutant variants were cloned downstream of the luciferase reporter into pMIRREPORT vector (Ambion). The sequences cloned were:
5'-UUUACAAUGUCAUAUACUGCCAU-3' (CCND1), 5'-UUUACAAUGUCAUAUUGACGGUU-3' (CCND1-mut), 5'-CAAUUAAUUUGUAAACACUGCCA-3' (E2F3), 5'-CAAUUAAUUUGUAAAGUGACGGA-3' (E2F3-mut). Cells were cultured in 24-well plates. Then, we added siPORT NeoFX Transfection Agent (AM4510, $1 \mu \mathrm{l}$; ABI, USA), pre-miR-449b (4464066, $40 \mathrm{nM}$; ABI)/miR-449b precursor molecule negative control $(4464058,40 \mathrm{nM}, \mathrm{ABI})$, pMIR-E2F3 $(0.1 \mu \mathrm{g})+\mathrm{pRL}-\mathrm{TK}$ vector $(0.01 \mu \mathrm{g}) / \mathrm{pMIR}-$ CCND1 $(0.1 \mu \mathrm{g})+$ pRL-TK vector $(0.01 \mu \mathrm{g}) / \mathrm{pMIR}-\mathrm{E} 2 \mathrm{~F} 3-\mathrm{mut}$ $(0.1 \mu \mathrm{g})+\mathrm{pRL}-\mathrm{TK}$ vector $(0.01 \mu \mathrm{g}) / \mathrm{pMIR}-\mathrm{CCND} 1-\mathrm{mut}$ $(0.1 \mu \mathrm{g})+$ pRL-TK vector $(0.01 \mu \mathrm{g})$ into $25 \mu \mathrm{l}$ of Opti-MEM medium. Then, $450 \mu \mathrm{l}$ of cell suspension containing 20,000 cells were added into the above-mentioned reagents. The 24-well plates were placed into the cell culture incubator and cell proliferation was observed with an optical microscope at 24 and $48 \mathrm{~h}$. Cell lysates were used for Dual-Luciferase ${ }^{\circledR}$ Reporter Assay System analysis, according to the manufacturer's instructions (Promega, Madison, WI, USA).

Transfection. We prepared pre-miR-449b precursor molecule, pre-miR-449b precursor molecule negative control and their inhibitors for transfection. SW116 cells were cultured in 6-well plates at $\sim 60 \%$ confluence. Cells were supplemented with siPORT NeoFX Transfection Agent (ABI, AM4510, USA) after $24 \mathrm{~h}$. We replaced siPORT NeoFX Transfection Agent with complete medium containing FCS $6 \mathrm{~h}$ later. To complete real-time PCR and western blot analyses, we lysated cells $48 \mathrm{~h}$ after transfection.

Cell growth and viability test. Tetrazolium blue method (MTT) was used to determine cell growth and viability. Cells in each group were seeded in 96-well plates. Each group had three parallel holes and each hole was supplemented with $5 \mathrm{mg} / \mathrm{ml}$ MTT $20 \mu \mathrm{l}$ after culturing cells for $48 \mathrm{~h}$. Then, dimethyl sulfoxide (DMSO) $150 \mu \mathrm{l}$ was added after incubating for $4 \mathrm{~h}$. The microplate reader determined the absorbance value (A) of each well at $640 \mathrm{~nm}$ wavelength. Proliferation ratio represents the extent of cell proliferation. Proliferation ratio $=\mathrm{A}$ value of experimental group/control group A value x 100\%.

Cell cycle test. The treated cells were cultured for $72 \mathrm{~h}$ before washing with PBS. The cells were fixed overnight using ice ethanol $\left(70 \%, 4^{\circ} \mathrm{C}\right)$. Cells were stained for $30 \mathrm{~min}$ with PI (Sigma, St. Louis, MO, USA). Cell cycle analyses were performed with the FACSCalibur (Becton-Dickinson). CellQuest (BD Bioscience, San Jose, CA, USA) was used as data analyzing software.

Western blot analysis. We washed and lysed cells with lysis buffer. Lysates were centrifuged to collect supernatants. Protein was denatured and separated in 10\% SDS-PAGE and was then transferred to nitrocellulose membranes. Non-fat milk (5\%) was used to block nitrocellulose membranes. The membranes were incubated with antibodies against CCND1, E2F3, pRb, Rb and p53 overnight and we then incubated membranes with secondary antibodies (horseradish peroxidase; Santa Cruz Biotechnology, Santa Cruz, CA, USA). Using the ECL procedure (Amersham Biosciences, Piscataway, NJ, USA), we detected secondary antibodies. 

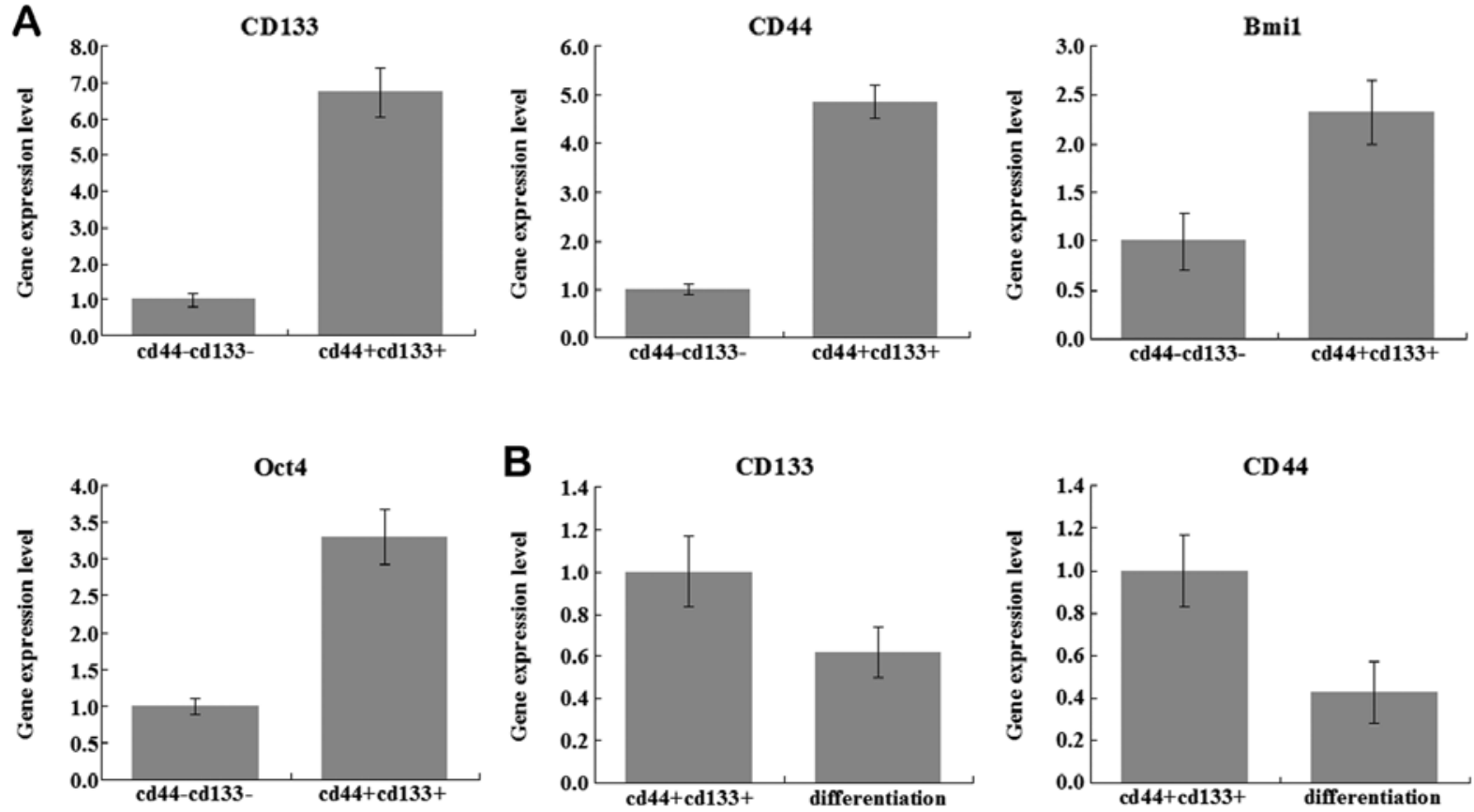

Figure 1. (A) A few stem cell-specific molecular expression levels in two groups of cells using real-time PCR. The chart shows that CD133, CD44, Bmi1 and Oct4 in the $\mathrm{CD} 44^{+} \mathrm{CD} 133^{+}$group have a higher expression level. (B) Expression levels of CD133, CD44 reduced after stem cell differentiation.

\section{Results}

$\mathrm{CD} 33^{+} \mathrm{CD} 44^{+}$colon stem cell isolation and stem characteristics. Several studies have proved that CD133 and CD44 were powerful markers to detect colon cancer stem cells (45-51). We isolated $\mathrm{CD} 133^{+} \mathrm{CD} 44^{+}$and $\mathrm{CD} 133{ }^{-} \mathrm{CD} 44^{-}$cells from the SW1116 cell line with FACS as we previously reported (44). Following amplification, flow cytometry was used to detect cell surface molecules (CD133 and CD44). Using real-time PCR, we examined several stem cell-specific molecule expression levels; CD133, CD44, Bmi1 and Oct4. In the CD133 ${ }^{+}$CD $44^{+}$ group, the expression levels of these specific molecules were higher than in the CD133-CD44- group (Fig. 1A). In the cell culture process, the $\mathrm{CD} 133^{+} \mathrm{CD} 44^{+}$cells can be gathered to become balls of cells after $\sim 10$ days of culture, with EGF and $\beta$-EGF in serum-free medium. Then, we moved the $\mathrm{CD} 133^{+} \mathrm{CD} 44^{+}$cells to normal medium culture. Cells gradually restored the adherent nature. At the same time, we found that the expression level of CD133, CD44 was also decreased (Fig. 1B). Our study confirmed that the CD133 ${ }^{+} \mathrm{CD} 44^{+}$cells possess stem cell phenotype, the specific molecular characteristics, the nature of self-renewal and directed differentiation.

Differential microRNA expression profile in colon cancer stem cells. With microRNA chip, we investigated the differential microRNA expression profile in $\mathrm{CD} 133^{+} \mathrm{CD} 44^{+}$colon cancer stem cells. We previously reported that there are 31 miRNAs upregulated and 31 miRNAs downregulated comparing the two groups (44). miR-449b was included in the most significantly downregulated list, whose average ratio was 0.486804 $\left(\mathrm{CD}^{3} 33^{+} \mathrm{CD} 44^{+}\right.$cells vs. CD133-CD44- cells).

Prediction of the target gene of miR-449b. We thoroughly searched the microRNA database (PicTar, TarBase, TargetScan and DIANA microT) bioinformatics technical analysis to predict the candidate miR-449b target gene mRNA. The 3'UTRs of CCND1 and E2F3 contain miR-449 binding sites (Fig. 2A). Thus, CCND1 and E2F3 may target genes of miR-449b.

CCND1, E2F3 and miR-449b correlate inversely in colon cancer stem cells. We verified the expression level of miR-449b in $\mathrm{CD}_{133}{ }^{+} \mathrm{CD} 44^{+}$cells and CD133-CD44- cells (Fig. 2C). miR-449b expression in the $\mathrm{CD} 133^{+} \mathrm{CD} 44^{+}$cells is only 0.455 times in the CD133-CD44 cells. Then, we examined protein levels of CCND1 and E2F3 (Fig. 2B). Based on the above, CCND1, E2F3 and miR-449b correlate inversely.

miR $449 b$ regulates $C C N D 1$ and $E 2 F 3$ expression in colon cancer stem cells. We tested CCND1 and E2F3 protein and mRNA expression levels to evaluate the effect of miR-449b transfection. The experiment set two groups of negative control; the blank control group and the pre-miR-449b negative control group. The inhibitors of pre-miR-449b and pre-miR-449b negative control were also analyzed. In our experiment, transfection of pre-miR-449b reduced the expression level of protein of CCND1 and E2F3. However, the expression levels of mRNA of CCND1 and E2F3 presented only minor changes. Moreover, the transfection of miR-449b inhibitor led to the overexpression of protein of CCND1 and E2F3. The change of mRNA level was not very sensitive (Fig. 3).

As the putative binding site of miR-449b in mRNA 3'-UTR region of CCND1 and E2F3, a Dual-Luciferase assay was performed to determine the direct link between CCND1, E2F3 and mir-449b. The mRNA region of CCND1 and E2F3 containing the miR-449b putative binding site and mutant variants were cloned into pMIR-REPORT vector. In Fig. 4, fluorescence activity was significantly reduced in the 
A

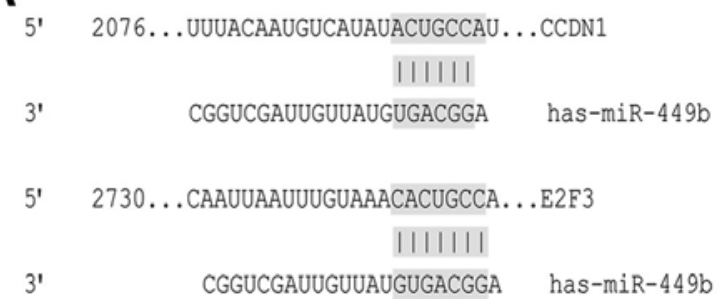

B

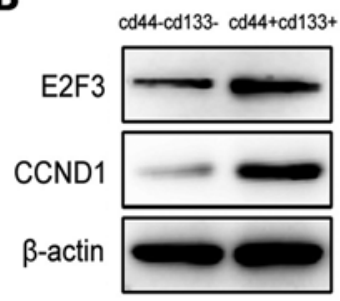

C

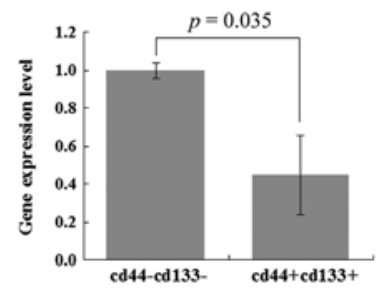

Figure 2. (A) The 3'UTRs of CCND1 and E2F3 contain miR-449 binding sites. (B) The difference of CCND1 and E2F3 protein expression levels between $\mathrm{CD} 133^{+} \mathrm{CD}_{4} 4^{+}$and CD133-CD44- cells. (C) We confirmed differences in the expression levels of miR-449b in the two groups of cells using real-time PCR.
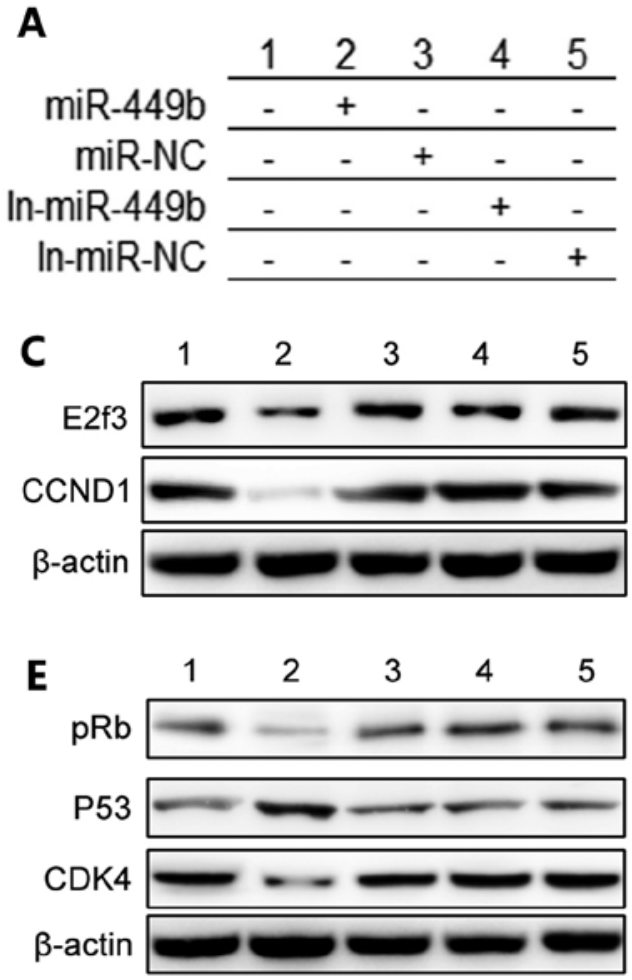
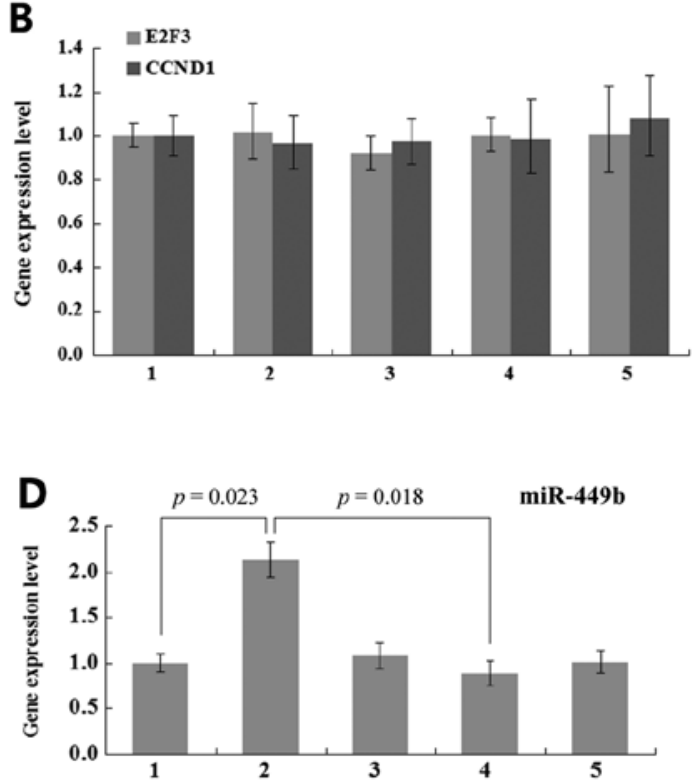

Figure 3. (A) miR-449b, miR-449b negative control, miR-449b-inhibitor, miR-449b-inhibitor negative control and blank control were added to cells, constituting five experimental groups. (B) The changes of CCND1 and E2F3 mRNA expression. (C) The changes of protein expression levels of CCND1 and E2F3. (D) We used real-time PCR to verify miR-449b expression level after transfection. (E) Expression levels of some cell cycle regulatory proteins and oncogenes, such as pRb, P53, CDK4, also changed.

pMIR-CCND1 + pre-miR-449b group and in the pMIR-E2F3 + pre-miR-449b group. Meanwhile, we found that transfecting miR-449b inhibitor can increase the fluorescent expression while transfecting with pre-miR-449b negative control had no effect (Fig. 4).

miR-449b influences cell growth and viability. As mentioned above, the expression of CCND1 and E2F3 can promote the role of cell proliferation. Therefore, miR-449b can be defined as a factor for the inhibition of cancer. In this experiment, we detected cell proliferation in each group by MTT assay. We observed cells in each group at different times after transfection and we found that the pre-miR-449b group lost its ability of proliferation significantly after $48 \mathrm{~h}$. Conversely, in the miR-449b inhibitor group, the proliferation ability of cells increased slightly after $72 \mathrm{~h}$ (Fig. 5).
miR-449b affects the cell cycle. According to the above findings, miR-449b has the ability to arrest cell cycle through controlling CCND1 and E2F3. A flow cytometer was used to analyze the cell cycle of all treatment groups. We found most of the pre-miR-449b group of cells in G phases. Accordingly, the number of this group in the $S$ phase was significantly reduced. Other group processing by the miR-449b inhibitor, cells in $\mathrm{G}$ phases were relatively reduced while cells in $\mathrm{S}$ phase had a small increase (Fig. 6).

Expression level of pathway-related molecules. By treating miR449b, we changed the expression level of its target genes. This affects the expression levels of other interrelated molecules in the pathway. Through the detection of $\mathrm{pRb}, \mathrm{p} 53$, and CDK4 molecular levels, we found an increased level of expression of these molecules in the pre-miR-449b group (Fig. 3E). 
A
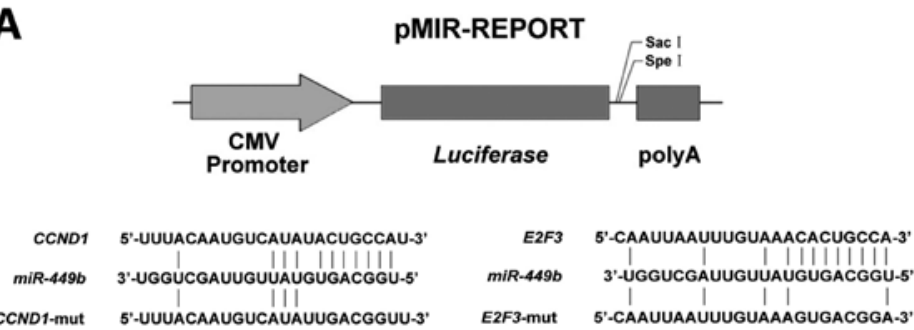

B

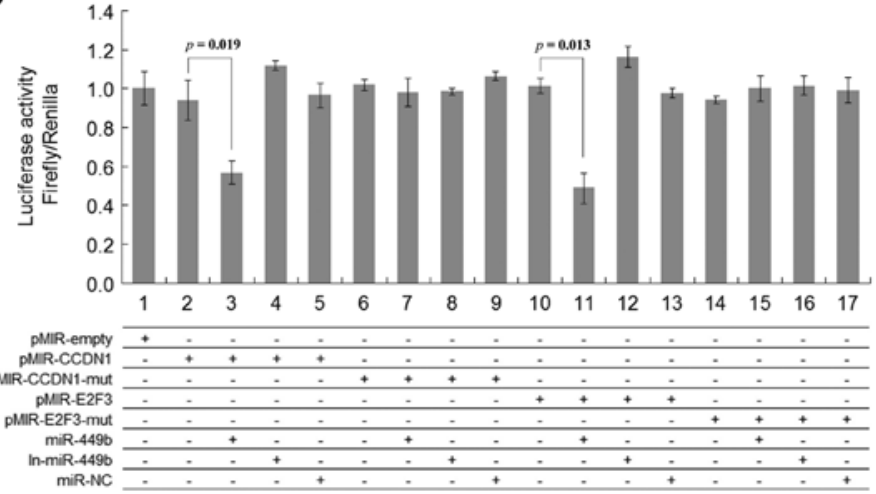

Figure 4. (A) We transformed CCND1, E2F3 and their mutants into the pMIR-REPORT vector. (B) A luciferase assay was carried out using pMIR-CCND1, pMIR-CCND1-mut, pMIR-E2F3 and pMIR-E2F3-mut reporter vectors. According to the requirements of the experiment, we designed 17 different experimental groups. Firefly luciferase activity was evaluated $48 \mathrm{~h}$ after transfection normalizing against Renilla luciferase activity.

A

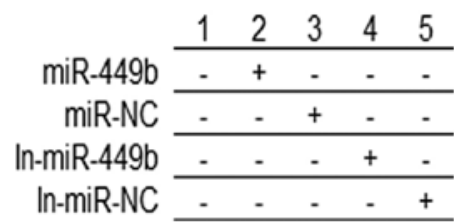

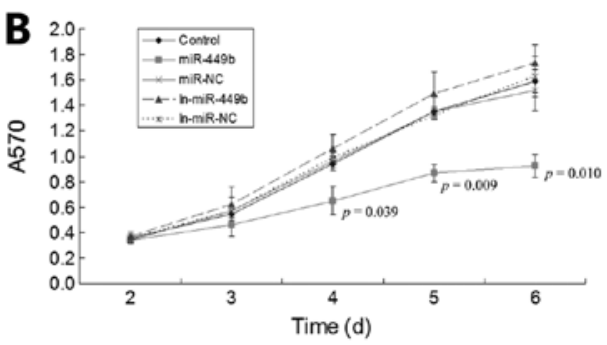

Figure 5. Growth and viability inhibition by miR-449b in colon cancer stem cells. We used MTT assay to analyze the cell growth and viability. We observed reduced cell growth and viability in the miR-449b group from 3 days after transfection.

A

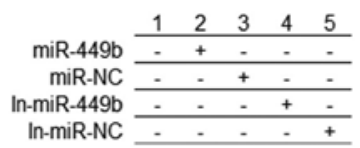

miR-NC

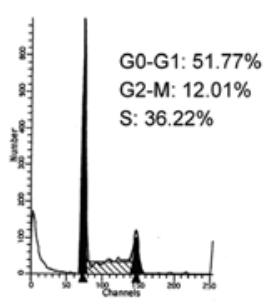

B

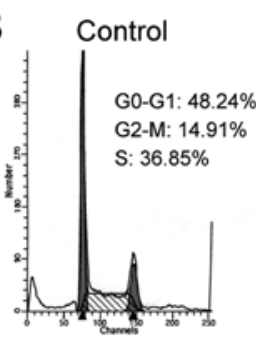

In-miR-449b

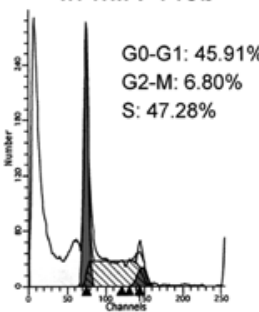

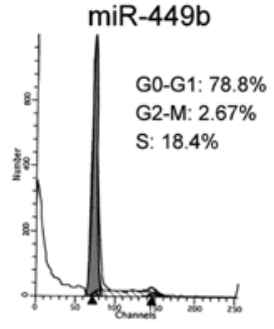

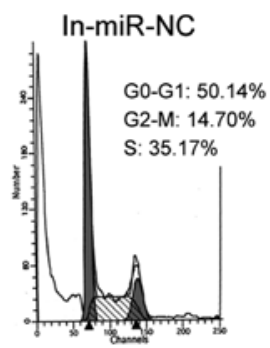

Figure 6. miR-449b arrests the cell cycle in colon cancer stem cells. The cells transfected with miR-449b, miR-449b negative control, miR-449b-inhibitor, miR-449b-inhibitor negative control were subjected to flow cytometry for the cell cycle test. We found that miR-449b increased the number of cells in the G0-G1 phases, reducing the number of cells in the S phase. 


\section{Discussion}

Previous studies suggested that differences of miRNA expression levels play an important role in the physiological function and phenotype of cells $(52,53)$. Cancer in various organs of the body have microRNA expression profile changes. Iorio et al (54) reported that overall miRNA expression can help separate normal vs. cancer tissues in human breast cancer. Michael et al (55) found 28 different miRNAs identified in a colonic adenocarcinoma and normal mucosa. They inhibited the expression of oncogenes while inhibiting the expression of tumor suppressor genes, directly or indirectly.

In cancer research, the hypothesis that cancer stem cells are the root of tumor cells has gained attention. With lineage tracing system, Schepers et al (56) confirmed a variety of different types of tumor cells from the same stem cells expressing $\mathrm{Lgr}^{+}$in mice. Moreover, these stem cells are the driving force of tumor development. Driessens et al (57) marked single tumor cells, while not specifically labeling stem cells. They found that cells exhibit two different modes of activities: before slowly depleting, they split a few or several cells. This again confirmed a unique type of cell subsets is the driving force of tumor growth. Therefore, the tumor stem cell hypothesis is a scientific explanation of the occurrence of cancer.

Based on these findings, it is evident that cancer stem cells are special groups in the tumor cells. Tumor stem cells may have a different microRNA expression profile vs. nonstem cell groups. Liu et al (58) showed miR-34a, a p53 target, was underexpressed in $\mathrm{CD} 44^{+}$prostate cancer cells, and they confirmed that miR-34a inhibits prostate cancer stem cells and metastasis by directly suppressing CD44. Godlewski et al (59) showed that miR-128 caused a striking decrease in the expression of the Bmi-1 oncogene, which is also a stem cell renewal factor. Through access to the microRNA database, several target genes of differentially expressing microRNAs are closely related to the special biology phenotype of stem cells. Possible target genes which have functions such as self-renewal, differentiation, membrane receptor connection, metabolism, tumor-related function are all regulated by differentially expressing microRNAs.

Through further bioinformatics analysis, we found that the expression levels of miR-449b and CCND1, E2F3 in colon cancer stem cells and stem cells are negatively correlated. CCND1, E2F3 have been proved to have the function of controlling cell cycle. The same family members of miR-449b, miR-449a have also been shown to be closely related to the miR-34 family. Target genes and target pathways of the miR-34 family are closely related to cell cycle regulation (29). Therefore, miR-449b may also be related to the regulation of colon cancer stem cell cycle. To prove this hypothesis, we transfected the precursor of miR-449b and miR-449b inhibitor into the colon cancer stem cells. As the colon cancer stem cell hypothesis demonstrated, the expression level of CCND1, E2F3 and miR-449b correlated inversely after transfection. However, this does not suffice to prove miR449b directly regulated CCND1 and E2F3 through a silencing mechanism, nor through other cellular factors or pathways. We performed a Dual-Luciferase assay to prove this. We co-transfected miR-449b precursor and reporter vectors containing E2F3 and CCND1 into cells. A decrease in luciferase activity in groups containing microRNA precursors and gene sequence reporter vectors was successfully observed. This confirmed direct interaction between CCND1, E2F3 and miR-449b. When we transfected mutants, these phenomena were not observed. At the same time, we explored the regulatory mechanism by which miR449b regulates E2F3 and CCND1. The change of the target gene mRNA levels is less than the protein level change. Thus, our evidence indicates that miR-449b uses two ways to regulate target genes, degradation and reversible combination.

We further studied the role of miR-449b in the colon cancer stem cell cycle regulation. In the group transfected with precursor of miR-449b, the number of cells in the G0-G1 phase increased significantly. In the group transfected with inhibitor of miR-449b, the opposite phenomenon was observed; the number of cells in the G0-G1 phase decreased. This is also consistent with the regulation of cell cycle function of E2F3 and CCND1. Similar to the above, miR-449b also influences cell growth and viability. By MTT assay, we found that the transfection of miR-449b precursors significantly reduced the proliferation ability of colon cancer stem cells; this may also be achieved through miR-449b direct regulation of E2F3, CCND1. It was also consistent with the phenomenon of E2F3 and CCND1 regulated by microRNAs confirmed by previous reports $(38,39,60,61)$. These confirmed that miR- $449 \mathrm{~b}$ has a certain influence on cell proliferation. Based on these, miR$449 \mathrm{~b}$, as its family member miR-449a (29), plays a role of the tumor suppressor gene.

In general, the regulation of cell signal is a unified system. In the present study the colon cancer stem cell expression levels of miR-449b changed. The level of its target genes also changed. Some pathway-related molecule expression levels have changed. In this study, in the $\mathrm{pRb}$ pathway, if active, the complex of CCND-CDK4/6-Rb, Rb can be phosphorylated, promoting cells from $\mathrm{G} 1$ to $\mathrm{S}$ phase. By inhibiting the expression of the Arf gene, E2F3 can inhibit the expression of p53. This may result in p53 tumor suppressor pathway dysfunction, promoting tumor development. We have also seen these molecule expression levels changed. This also shows miR-449b regulating cell cycle and proliferation not only through E2F3 and CCND1, but also through alteration of other molecules. miR- $449 \mathrm{~b}$ indirectly enhances p53 expression levels in colon cancer stem cells providing key evidence to prove its tumor suppressor role.

In conclusion, our study shows that miR-449b may have a direct relationship with E2F3 and CCND1 in colon cancer stem cells in vitro. Notably, miR-449b can regulate the expression level of E2F3 and CCND1 through the post-transcriptional regulation. These in turn affect cell cycle regulation and proliferation characteristics. The regulatory pathway related molecules also change their expression levels. Regulating the expression levels of miR-449b can affect a number of important stem cell phenotypes in colon cancer stem cells. We can use it to prevent the self-renewal and proliferation of colon cancer stem cell, as the source of the colon cancer cells. miR- $449 \mathrm{~b}$ may become an important target in the treatment of colon cancer in the future. 


\section{References}

1. Jemal A, Siegel R, Ward E, Hao Y, Xu J and Thun MJ: Cancer statistics, 2009. CA Cancer J Clin 59: 225-249, 2009.

2. Van Loon K and Venook AP: Adjuvant treatment of colon cancer: what is next? Curr Opin Oncol 23: 403-409, 2011

3. Garcia-Foncillas J and Diaz-Rubio E: Progress in metastatic colorectal cancer: growing role of cetuximab to optimize clinical outcome. Clin Transl Oncol 12: 533-542, 2010

4. Clevers $\mathrm{H}$ : The cancer stem cell: premises, promises and challenges. Nat Med 17: 313-319, 2011.

5. Jiao X, Katiyar S, Willmarth NE, et al: c-Jun induces mammary epithelial cellular invasion and breast cancer stem cell expansion. J Biol Chem 285: 8218-8226, 2010.

6. Sullivan JP and Minna JD: Tumor oncogenotypes and lung cancer stem cell identity. Cell Stem Cell 7: 2-4, 2010.

7. Li H and Tang DG: Prostate cancer stem cells and their potential roles in metastasis. J Surg Oncol 103: 558-562, 2011.

8. Zeki SS, Graham TA and Wright NA: Stem cells and their implications for colorectal cancer. Nat Rev Gastroenterol Hepatol 8: 90-100, 2011

9. Silva IA, Bai S, McLean K, et al: Aldehyde dehydrogenase in combination with CD133 defines angiogenic ovarian cancer stem cells that portend poor patient survival. Cancer Res 71: 3991-4001, 2011.

10. Baba T, Convery PA, Matsumura N, et al: Epigenetic regulation of CD133 and tumorigenicity of $\mathrm{CD}_{133}{ }^{+}$ovarian cancer cells. Oncogene 28: 209-218, 2009.

11. Landen CN Jr, Goodman B, Katre AA, et al: Targeting aldehyde dehydrogenase cancer stem cells in ovarian cancer. Mol Cancer Ther 9: 3186-3199, 2010.

12. Kurrey NK, Jalgaonkar SP, Joglekar AV, et al: Snail and slug mediate radioresistance and chemoresistance by antagonizing p53-mediated apoptosis and acquiring a stem-like phenotype in ovarian cancer cells. Stem Cells 27: 2059-2068, 2009.

13. Qiang L, Yang Y, Ma YJ, et al: Isolation and characterization of cancer stem like cells in human glioblastoma cell lines. Cancer Lett 279: 13-21, 2009.

14. Bartel DP: MicroRNAs: genomics, biogenesis, mechanism, and function. Cell 116: 281-297, 2004.

15. Kim VN and Nam JW: Genomics of microRNA. Trends Genet 22: 165-173, 2006

16. Shyu AB, Wilkinson MF and van Hoof A: Messenger RNA regulation: to translate or to degrade. EMBO J 27: 471-481, 2008

17. Garzon R, Fabbri M, Cimmino A, Calin GA and Croce CM MicroRNA expression and function in cancer. Trends Mol Med 12: 580-587, 2006

18. Nicoloso MS, Spizzo R, Shimizu M, Rossi S and Calin GA: MicroRNAs - the micro steering wheel of tumour metastases. Nat Rev Cancer 9: 293-302, 2009.

19. Chan JA, Krichevsky AM and Kosik KS: MicroRNA-21 is an antiapoptotic factor in human glioblastoma cells. Cancer Res 65 6029-6033, 2005.

20. Lu J, Getz G, Miska EA, et al: MicroRNA expression profiles classify human cancers. Nature 435: 834-838, 2005.

21. Zhang H, Li W, Nan F, et al: MicroRNA expression profile of colon cancer stem-like cells in HT29 adenocarcinoma cell line. Biochem Biophys Res Commun 404: 273-278, 2011.

22. Yu F, Deng H, Yao H, Liu Q, Su F and Song E: Mir-30 reduction maintains self-renewal and inhibits apoptosis in breast tumorinitiating cells. Oncogene 29: 4194-4204, 2010.

23. Iliopoulos D, Lindahl-Allen M, Polytarchou C, Hirsch HA Tsichlis PN and Struhl K: Loss of miR-200 inhibition of Suz12 leads to polycomb-mediated repression required for the formation and maintenance of cancer stem cells. Mol Cell 39: 761-772, 2010.

24. Qian S, Ding JY, Xie R, et al: MicroRNA expression profile of bronchioalveolar stem cells from mouse lung. Biochem Biophys Res Commun 377: 668-673, 2008.

25. Silber J, Lim DA, Petritsch C, et al: miR-124 and miR-137 inhibit proliferation of glioblastoma multiforme cells and induce differentiation of brain tumor stem cells. BMC Med 6: 14, 2008.

26. Ji Q, Hao X, Zhang M, et al: MicroRNA miR-34 inhibits human pancreatic cancer tumor-initiating cells. PloS One 4: e6816, 2009.

27. Ma L, Li N, He X and Zhang Q: miR-449b and miR-34c on inducing down-regulation of cell cycle-related proteins and cycle arrests in SKOV3-ipl cell, an ovarian cancer cell line. Beijing Da Xue Xue Bao 43: 129-133, 2011 (In Chinese).
28. Bou Kheir T, Futoma-Kazmierczak E, Jacobsen A, et al: miR-449 inhibits cell proliferation and is down-regulated in gastric cancer. Mol Cancer 10: 29, 2011.

29. Chen H, Lin YW, Mao YQ, et al: MicroRNA-449a acts as a tumor suppressor in human bladder cancer through the regulation of pocket proteins. Cancer Lett 320: 40-47, 2012.

30. Matsushime H, Roussel MF, Ashmun RA and Sherr CJ: Colonystimulating factor 1 regulates novel cyclins during the G1 phase of the cell cycle. Cell 65: 701-713, 1991.

31. Buchkovich K, Duffy LA and Harlow E: The retinoblastoma protein is phosphorylated during specific phases of the cell cycle. Cell 58: 1097-1105, 1989.

32. Chen PL, Scully P, Shew JY, Wang JY and Lee WH: Phosphorylation of the retinoblastoma gene product is modulated during the cell cycle and cellular differentiation. Cell 58: 1193-1198, 1989

33. Weinberg RA: The retinoblastoma protein and cell cycle control. Cell 81: 323-330, 1995.

34. Harbour JW, Luo RX, Dei Santi A, Postigo AA and Dean DC: Cdk phosphorylation triggers sequential intramolecular interactions that progressively block Rb functions as cells move through G1. Cell 98: 859-869, 1999.

35. Reis-Filho JS, Savage K, Lambros MB, et al: Cyclin D1 protein overexpression and CCND1 amplification in breast carcinomas: an immunohistochemical and chromogenic in situ hybridisation analysis. Mod Pathol 19: 999-1009, 2006.

36. Hosokawa Y and Arnold A: Mechanism of cyclin D1 (CCND1, PRAD1) overexpression in human cancer cells: analysis of allelespecific expression. Genes Chromosomes Cancer 22: 66-71, 1998.

37. Betticher DC, Heighway J, Hasleton PS, et al: Prognostic significance of CCND1 (cyclin D1) overexpression in primary resected non-small-cell lung cancer. Br J Cancer 73: 294-300, 1996.

38. Leone G, DeGregori J, Yan Z, et al: E2F3 activity is regulated during the cell cycle and is required for the induction of $\mathrm{S}$ phase. Genes Dev 12: 2120-2130, 1998.

39. Humbert PO, Verona R, Trimarchi JM, Rogers C, Dandapani S and Lees JA: E2f3 is critical for normal cellular proliferation. Genes Dev 14: 690-703, 2000.

40. Oeggerli M, Tomovska S, Schraml P, et al: E2F3 amplification and overexpression is associated with invasive tumor growth and rapid tumor cell proliferation in urinary bladder cancer. Oncogene 23: 5616-5623, 2004.

41. Olsson AY, Feber A, Edwards S, et al: Role of E2F3 expression in modulating cellular proliferation rate in human bladder and prostate cancer cells. Oncogene 26: 1028-1037, 2007.

42. Cooper CS, Nicholson AG, Foster C, et al: Nuclear overexpression of the E2F3 transcription factor in human lung cancer. Lung Cancer 54: 155-162, 2006.

43. Pierce AM, Gimenez-Conti IB, Schneider-Broussard R, Martinez LA, Conti CJ and Johnson DG: Increased E2F1 activity induces skin tumors in mice heterozygous and nullizygous for p53. Proc Natl Acad Sci USA 95: 8858-8863, 1998.

44. Fang Y, Xiang J, Chen Z, et al: miRNA expression profile of colon cancer stem cells compared to non-stem cells using the SW1116 cell line. Oncol Rep 28: 2115-2124, 2012.

45. Ieta K, Tanaka F, Haraguchi N, et al: Biological and genetic characteristics of tumor-initiating cells in colon cancer. Ann Surg Oncol 15: 638-648, 2008.

46. O'Brien CA, Pollett A, Gallinger S and Dick JE: A human colon cancer cell capable of initiating tumour growth in immunodeficient mice. Nature 445: 106-110, 2007.

47. Ricci-Vitiani L, Lombardi DG, Pilozzi E, et al: Identification and expansion of human colon-cancer-initiating cells. Nature 445 : 111-115, 2007.

48. Vermeulen L, Todaro M, de Sousa Mello F, et al: Single-cell cloning of colon cancer stem cells reveals a multi-lineage differentiation capacity. Proc Natl Acad Sci USA 105: 13427-13432, 2008.

49. Al-Hajj M, Wicha MS, Benito-Hernandez A, Morrison SJ and Clarke MF: Prospective identification of tumorigenic breast cancer cells. Proc Natl Acad Sci USA 100: 3983-3988, 2003.

50. Dalerba P, Dylla SJ, Park IK, et al: Phenotypic characterization of human colorectal cancer stem cells. Proc Natl Acad Sci USA 104: 10158-10163, 2007.

51. Li C, Heidt DG, Dalerba P, et al: Identification of pancreatic cancer stem cells. Cancer Res 67: 1030-1037, 2007.

52. Wang HJ, Ruan HJ, He XJ, et al: MicroRNA-101 is downregulated in gastric cancer and involved in cell migration and invasion. Eur J Cancer 46: 2295-2303, 2010. 
53. Wang X, Lam EK, Zhang J, Jin H and Sung JJ: MicroRNA-122a functions as a novel tumor suppressor downstream of adenomatous polyposis coli in gastrointestinal cancers. Biochem Biophys Res Commun 387: 376-380, 2009.

54. Iorio MV, Ferracin M, Liu CG, et al: MicroRNA gene expression deregulation in human breast cancer. Cancer Res 65: 7065-7070, 2005 .

55. Michael MZ, SM OC, van Holst Pellekaan NG, Young GP and James RJ: Reduced accumulation of specific microRNAs in colorectal neoplasia. Mol Cancer Res 1: 882-891, 2003.

56. Schepers AG, Snippert HJ, Stange DE, et al: Lineage tracing reveals $\mathrm{Lgr}^{+}$stem cell activity in mouse intestinal adenomas. Science 337: 730-735, 2012.

57. Driessens G, Beck B, Caauwe A, Simons BD and Blanpain C: Defining the mode of tumour growth by clonal analysis. Nature 488: 527-530, 2012
58. Liu C, Kelnar K, Liu B, et al: The microRNA miR-34a inhibits prostate cancer stem cells and metastasis by directly repressing CD44. Nat Med 17: 211-215, 2011.

59. Godlewski J, Nowicki MO, Bronisz A, et al: Targeting of the Bmi-1 oncogene/stem cell renewal factor by microRNA-128 inhibits glioma proliferation and self-renewal. Cancer Res 68: 9125-9130, 2008

60. Sun F, Fu H, Liu Q, et al: Downregulation of CCND1 and CDK6 by miR-34a induces cell cycle arrest. FEBS Lett 582: 1564-1568, 2008.

61. Aslanian A, Iaquinta PJ, Verona R and Lees JA: Repression of the Arf tumor suppressor by E2F3 is required for normal cell cycle kinetics. Genes Dev 18: 1413-1422, 2004. 